\title{
Neurologic and psycho-intellectual outcome related to structural brain imaging in adolescents and young adults after neonatal arterial switch operation for transposition of the great arteries
}

\author{
Anna Kathrin M. Heinrichs, ${ }^{a}$ Annika Holschen, MD, ${ }^{a}$ Timo Krings, MD, ${ }^{b}$ Bruno J. Messmer, MD, \\ Ralph Schnitker, PhD, ${ }^{\mathrm{d}}$ Ralf Minkenberg, Dipl-Phys, ${ }^{\mathrm{e}}$ and Hedwig H. Hövels-Gürich, MD ${ }^{\mathrm{a}}$
}

\begin{abstract}
Objective: We studied brain structure abnormalities in adolescents and young adults who had undergone the neonatal arterial switch operation for transposition of the great arteries and related them to the neurologic and psycho-intellectual outcomes.
\end{abstract}

\begin{abstract}
Methods: In a prospective longitudinal study, 60 unselected adolescents and young adults who had undergone surgery with combined deep hypothermic circulatory arrest and low flow cardiopulmonary bypass were re-evaluated at a mean age of $16.9 \pm 1.7$ years to determine their clinical neurologic status, intellectual development, and psychological condition. The results were related to population norms and anatomic structural abnormalities assessed by brain magnetic resonance imaging, with consideration of the risk factors in the preoperative and perioperative periods.
\end{abstract}

\begin{abstract}
Results: Neurologic impairment was more frequent $(10 \%)$ than in the normal population. Although the average full-scale, verbal, and performance intelligence quotients were not reduced, scores $>2$ standard deviations less than the expected mean were increased. Above average scores were found for analytical thinking, but the orthography testing results were reduced. The self-rated psychological condition was better than expected. Magnetic resonance imaging demonstrated moderate or severe structural brain abnormalities in $32 \%$ of the patients. Periventricular leukomalacia was detected in $>50 \%$; its severity correlated with the grade of neurologic impairment, which correlated significantly with reduced intelligence, analytical thinking, and orthography. Preoperative acidosis and hypoxia were the only independent patient-related risk factors for neurologic dysfunction, reduced intelligence, periventricular leukomalacia, and reduced brain volume.
\end{abstract}

Conclusions: Despite encouraging overall neurodevelopmental outcomes, a significant minority had performances below the expected level, emphasizing the need for ongoing surveillance. Considering the high frequency of structural brain abnormalities, prospective long-term studies are needed to define their prognostic value with respect to the neuropsychological outcomes in childhood and adolescence. (J Thorac Cardiovasc Surg 2014;148:2190-9)

See related commentary on pages 2199-200.

Although the neonatal arterial switch operation (ASO) to correct transposition of the great arteries (TGA) has been accepted for $>25$ years as the method of choice because

From the Departments of Pediatric Cardiology, ${ }^{a}$ Neuroradiology, ${ }^{\mathrm{b}}$ Cardiothoracic Surgery, ${ }^{c}$ and Central Service Facility "Functional Imaging" at the ICCR-Biomat, ${ }^{\mathrm{d}}$ University Hospital, Aachen University of Technology, Aachen, Germany; and Boehringer Ingelheim Pharma GmbH \& Co KG, ${ }^{\mathrm{e}}$ Ingelheim, Germany.

The study was supported by grants from the Bundesverband Herzkranke Kinder e.V., Aachen, Germany.

Disclosures: Authors have nothing to disclose with regard to commercial support.

Received for publication Aug 5, 2013; revisions received Sept 23, 2013; accepted for publication Oct 6, 2013; available ahead of print June 18, 2014.

Address for reprints: Hedwig H. Hövels-Gürich, MD, Department of Pediatric Cardiology, University Hospital, Aachen University of Technology, Pauwelsstr 30, Aachen D-52057, Germany (E-mail: hhoevels-guerich@ukaachen.de).

$0022-5223 / \$ 36.00$

Copyright $(\odot) 2014$ by The American Association for Thoracic Surgery

http://dx.doi.org/10.1016/j.jtcvs.2013.10.087 of the low mortality and good long-term cardiologic results, longitudinal examination of the neurodevelopmental outcomes in adolescents and young adults has been very rare. ${ }^{1}$

Within our institution's prospective arterial switch reassessment program, the patients had been evaluated at a mean age of 5.4 years $^{2,3}$ and 10.5 years $^{4-6}$ after neonatal ASO, when they had presented with increased neurologic impairment but normal average intelligence scores. The parent-rated, but not self-rated, psychosocial stress was also elevated.

The purpose of the present study was to reassess our patients' neurologic status, formal intelligence, and psychological condition and to perform structural brain imaging. Our patients were adolescents and young adults from a large homogeneous group of unselected patients. Limited information is available concerning the risk factors for structural brain abnormalities, and the possible relations to neuropsychological outcomes in this age group need additional assessment. 

Abbreviations and Acronyms
ASO = arterial switch operation
$\mathrm{CPB}=$ cardiopulmonary bypass
$\mathrm{DHCA}=$ deep hypothermic circulatory arrest
IQ = intelligence quotient
MRI = magnetic resonance imaging
MRT = Mannheimer Rechtschreib test
$\mathrm{PVL}=$ periventricular leukomalacia
$\mathrm{SD}=$ standard deviation
SP = Spearman's correlation coefficient
TGA $=$ transposition of the great arteries
tMRI $=$ total structural brain MRI

\section{METHODS \\ Demographic Data}

From 1986 to 1992, 96 neonates with TGA had undergone ASO. The present study group consisted of 60 unselected adolescents and young adults ( $67 \%$ of the 89 long-term survivors), who had been re-evaluated at a mean \pm standard deviation $(\mathrm{SD})$ age of $16.9 \pm 1.7$ years (range, 14.0-21.1), $78.3 \%$ of whom were male. Of the 60 patients, $54(90 \%)$ had participated in both preceding studies at a mean age of 5.4 years $^{2,3}$ and 10.5 years, ${ }^{4-6}$ and $6(10 \%)$ had participated in the study at a mean age of 5.4 years and had been re-evaluated by questionnaire at a mean age of 10.5 years. Of the 60 patients, $74 \%$ had had simple TGA, and $18 \%$ had also had a nonimportant ventricular septal defect, and an additional $5 \%$ had an important ventricular septal defect that had been closed during ASO. Two patients had had coarctation of the aorta corrected during later infancy. Finally, $87 \%$ had undergone atrial balloon septostomy, and all had been treated with prostaglandin $\mathrm{E}_{1}$ before surgery to keep the arterial duct open. At re-evaluation, all patients, except for 2 with spastic tetraplegia and 1 with distinct scoliosis, had a normal endurance capacity as assessed by spiroergometry, and none was taking cardiac or psychiatric medication. The rate of attendance to special schools and the lack of a final school examination was $12 \%$ each. The socioeconomic status, evaluated according to the income producer's profession, was not different from that of a normal population. ${ }^{7}$

The present study was designed as a case series with published controls and prognostic factor analyses. The demographic data and risk factors for neurodevelopmental outcome are listed in Table 1. The ethical medical committee of the Aachen University of Technology (Aachen, Germany) approved the study, and all patients and their parents provided written informed consent.

\section{Surgical Management and Perfusion Methods}

The age at ASO ranged from 1 to 39 days (mean $7.1 \pm 5.1$ ); 2 patients were $>12$ days old. ASO was performed under conditions of deep hypothermic circulatory arrest (DHCA) and combined low flow cardiopulmonary bypass (CPB) by 2 surgeons (B.J.M., S.H.D.). The standardized surgical technique using the Lecompte modification and bypass modalities has been previously described. ${ }^{2}$ The CPB times are listed in Table 1.

\section{Neurologic Examination}

The clinical neurologic status was evaluated by an experienced examiner (H.H.H.-G.). The results were classified as normal or borderline without functional impairment (grade 0) or moderately (grade 1, functional impairment requiring therapy) or severely (grade 2, dependent on continued assistance) impaired. Neurologic dysfunction was diagnosed in patients who had $\geq 1$ of the following abnormalities: abnormal head shape or growth, abnormal cranial nerves, motor dyspraxia, ataxia, sensory dysfunction, palsy, clinical seizures during the previous 5 years, and dysreflexia.

\section{Psycho-Intellectual Testing}

The battery of tests focused on the evaluation of formal intelligence, academic achievement, and psychological condition. The tests were normalized for age and/or gender and were conducted by 2 examiners on 2 consecutive days within the scope of a standardized operative sequence.

Intelligence. The Hamburg-Wechsler intelligence test (German version of the Wechsler Adult Intelligence Scale, revised), ${ }^{8}$ with a possible mean score of $100 \pm 15$, was used to determine cognitive development and reduction of effort. Of the 60 patients, 56 were tested using 6 of 11 subtests (information, arithmetic, similarities, vocabulary, picture completion, and block design) to evaluate the verbal, performance, and full-scale intelligence quotient (IQ) (Table 2).

Analytical thinking. The Leistungsprüfsytem nach Horn ${ }^{9}$ is a standardized German intelligence test consisting of 14 subtests with a mean possible score of $100 \pm 15$. Subtest 3 (geometric shapes) was given to 56 patients to analyze analytical thinking as an indicator of the so-called fluid intelligence, which has been assumed to be inherited rather than acquired.

Orthographic performance. The Mannheimer Rechtschreib test $(\mathrm{MRT})^{10}$ is a German standardized test of orthography, defined as the assessment of spelling skills and mistakes. We used the long form, which consisted of 120 items. The 6 subtests, consisting of 20 items each (Table 2), represent different categories to identify key aspects of orthographic performance. The results of the subtests and a summary range are expressed as percentages and were compared with published normal values from an age-, graduation-, and province-matched German population.

Psychological condition. The Brief Symptom Inventory ${ }^{11}$ was used to obtain standardized information from 57 patients on their subjective psychological condition during the previous 7 days compared with that of healthy controls. In the Brief Symptom Inventory, 53 items have been subsumed into 9 symptom scales to provide psychometric information (somatization, obsessive-compulsive behavior, interpersonal sensitivity, depression, anxiety, hostility, phobic anxiety, paranoid ideation, psychoticism). From these scales, 3 global indexes can be derived: the Global Severity Index, measuring the overall psychological distress level and defining the patient's perception level of psychological problems; the Positive Symptom Distress Index, measuring the intensity of symptoms; and the Positive Symptom Total, indicating the number of self-reported symptoms. The test results are expressed as normalized $\mathrm{T}$ scores, with higher values representing increased psychological stress. The present study focused mainly on the Global Severity Index T score as the most sensitive factor for evaluating a patient's general psychological condition (Table 2).

\section{Structural Brain Imaging}

Structural brain magnetic resonance imaging (MRI) was performed in 54 patients to evaluate possible cortical and white matter abnormalities after exposure to an increased risk of preoperative, perioperative, and postoperative hypoxia and hypoperfusion of the brain. The exclusion criteria were a cardiac pacemaker or cochlea implant and noncompliance because of anxiety $(\mathrm{n}=4)$.

MRI was performed using a 3.0 Tesla Arechiva magnetic resonance scanner (Philips Healthcare, Best, The Netherlands). The scanning protocol included acquisition of the following images: T2-fluid attenuated inversion recovery, diffusion, T2* fast field echo (axial orientation), T2-turbo spin echo, and $\mathrm{T} 1 *$ fast field echo (sagittal orientation).

The MRI scans were evaluated by a neuroradiologist (T.K.), who was unaware of all clinical data, by visual inspection. Anatomic abnormalities were classified with respect to the following criteria: reduced brain volume (intrinsic volume loss [ventricular dilatation] and extrinsic volume loss [increased width of sulci] —evaluated separately), periventricular leukomalacia (PVL), focal non-periventricular white matter lesions, encephalomalacia, and additional abnormalities. Brain volume loss and PVL were classified into 4 grades: no abnormality (grade 0 ), mild (grade 1), moderate (grade 2), and severe abnormality (grade 3 ) (Table 3). In addition, a summary score of all criteria was determined, the total structural brain MRI 
TABLE 1. Patient characteristics

\begin{tabular}{|c|c|c|}
\hline Variable & Definition/Comment & Result \\
\hline Perinatal asphyxia & APGAR score $<7$ after 5 min & $13.3 \%(8 / 60)$ \\
\hline Severe preoperative acidosis and hypoxia & $\begin{array}{l}\text { pH value }<7.2 \text { in umbilical venous blood; severe } \\
\text { postasphyxia syndrome with organ failure and } \\
\text { cerebral seizures; repeated severe cyanosis caused by } \\
\text { intracardiac mixing problems }\end{array}$ & $15.0 \%(9 / 60)$ \\
\hline Age at surgery (d) & - & $7.1 \pm 5.1$ \\
\hline Temperature at DHCA initiation $\left({ }^{\circ} \mathrm{C}\right)$ & - & $15.1 \pm 1.0$ \\
\hline DHCA duration (min) & - & $60.2 \pm 3.3$ \\
\hline CPB duration (min) & - & $61.7 \pm 14.1$ \\
\hline Aortic crossclamping duration (min) & - & $65.4 \pm 7.4$ \\
\hline $\begin{array}{l}\text { Perioperative and postoperative cardiocirculatory } \\
\text { insufficiency }\end{array}$ & $\begin{array}{l}\text { Low cardiac output* despite adequate filling pressures } \\
\text { and inotropic and vasodilator therapy }\end{array}$ & $16.7 \%(10 / 60)$ \\
\hline Perioperative and postoperative resuscitation events & $\begin{array}{l}\text { Necessity for pharmacologic and/or mechanical } \\
\text { resuscitation }\end{array}$ & $6.7 \%(4 / 60)$ \\
\hline Postoperative IVH & $\begin{array}{l}\text { Evaluation by cranial ultrasonography preoperatively } \\
\text { and } 4 \mathrm{~h}, 1,2 \text {, and } 3 \mathrm{~d} \text {, and } 1 \text { and } 2 \text { wk postoperatively; } \\
\text { persistence of IVH-like findings } 2 \text { wk postoperatively }\end{array}$ & $6.7 \%(4 / 60)$ \\
\hline Perioperative and postoperative seizures & Determined by clinical examination & $3.3 \%(2 / 60)$ \\
\hline Age at neurodevelopmental re-evaluation (y) & - & $16.9 \pm 1.7$ \\
\hline Socioeconomic status & $\begin{array}{l}\text { Family's social classification according to income } \\
\text { producer's profession }\end{array}$ & $P=.69 \dagger$ vs published controls \\
\hline
\end{tabular}

Data presented as mean \pm standard deviation or $\%(\mathrm{n} / \mathrm{n}) . D H C A$, Deep hypothermic circulatory arrest; $C P B$, cardiopulmonary bypass; $I V H$, intraventricular cerebral hemorrhage. *Clinically estimated by arterial pressure (target value for mean pressure, $45 \mathrm{~mm} \mathrm{Hg}$ ), central venous pressure (target value, $5-7 \mathrm{~mm} \mathrm{Hg}$ ), diuresis (target value, $>1.5 \mathrm{~mL} / \mathrm{kg}$ body weight/h), capillary refill time, and skin temperature. $\dagger P$ value calculated by comparison of frequencies, with socioeconomic status representing an ordinal scale.

(tMRI) score, which was classified into 3 grades: no or mild abnormality (grade 0 , all criteria classified as normal or mild), moderate abnormality (grade $1, \geq 1$ criteria classified as moderate), and severe structural brain abnormality (grade $2, \geq 1$ criteria classified as severe).

\section{Statistical Analysis}

The results are expressed as the mean \pm standard deviation or percentages. For the comparison of the mean values, $t$ tests were applied. For intergroup comparisons of the clinical variables, the nonparametric

TABLE 2. Psycho-intellectual outcome parameters compared with population norms

\begin{tabular}{|c|c|c|c|c|c|}
\hline \multirow[b]{2}{*}{ Developmental test } & \multirow[b]{2}{*}{ Normal score } & \multirow[b]{2}{*}{ Patient score } & \multirow[b]{2}{*}{$P$ value* } & \multicolumn{2}{|c|}{ Abnormal patient results $\dagger(\%)$} \\
\hline & & & & $\leq \mathbf{1}$ SD & $\leq \mathbf{2}$ SD \\
\hline \multicolumn{6}{|l|}{ HAWIE- $^{8}(\mathrm{n}=56)($ standard $)$} \\
\hline Verbal IQ & $100 \pm 15$ & $104.2 \pm 22.6$ & .17 & 8.9 & 1.8 \\
\hline Performance IQ & $100 \pm 15$ & $105.4 \pm 27.5$ & .14 & 14.3 & 10.7 \\
\hline Full-scale IQ & $100 \pm 15$ & $106.7 \pm 23.1$ & .03 & 8.9 & 5.4 \\
\hline \multicolumn{6}{|l|}{$\operatorname{LPS}^{9}(\mathrm{n}=56)$} \\
\hline Analytical thinking & $100 \pm 15$ & $120 \pm 12.5$ & $<.001$ & 0 & 0 \\
\hline \multicolumn{6}{|l|}{$\mathrm{MRT}^{10}(\mathrm{n}=56)$ (percentage range) } \\
\hline Lengthening of vowels & $50 \pm 34$ & $24.6 \pm 22.8$ & $<.001$ & 37.5 & 5.4 \\
\hline Shortening of vowels & $50 \pm 34$ & $46.4 \pm 29.2$ & .36 & 12.5 & 8.9 \\
\hline Confusion of consonants & $50 \pm 34$ & $36.3 \pm 25.4$ & $<.001$ & 12.5 & 8.9 \\
\hline Confusion of vowels & $50 \pm 34$ & $30.3 \pm 27.1$ & $<.001$ & 35.7 & 8.9 \\
\hline Capitalization, separate, compound writing & $50 \pm 34$ & $34.0 \pm 24.5$ & $<.001$ & 25.0 & 3.5 \\
\hline Foreign words & $50 \pm 34$ & $45.4 \pm 30.1$ & .26 & 17.9 & 7.1 \\
\hline Orthography summary range & $50 \pm 34$ & $31.2 \pm 24.3$ & $<.001$ & 19.6 & 16.1 \\
\hline \multicolumn{6}{|l|}{$\mathrm{BSI}^{11}(\mathrm{n}=57)(\mathrm{T}$ score $)$} \\
\hline T-GSI & 53.4 & $49.6 \pm 12.7$ & .009 & 5.3 & $1.8 \ddagger$ \\
\hline T-PSDI & 52.8 & $52.3 \pm 12.3$ & .062 & & \\
\hline
\end{tabular}

Data presented as mean $\pm \mathrm{SD}$, unless otherwise noted. $S D$, Standard deviation; HAWIE-R, Hamburg-Wechsler intelligence test, revised; $I Q$, intelligence quotient; $L P S$, Leistungsprüfsystem nach Horn; MRT, Mannheimer Rechtschreib test; BSI, Brief Symptom Inventory; T-GSI, T score of Global Severity Index; T-PSDI, T score of Positive Symptom Distress Index. $* P$ values calculated by comparison of mean values; normal and abnormal results compared with normal published values. ${ }^{8-11} \dagger{ }^{\dagger}$ Reduced $=\leq 1$ SD or $\leq 2$ SD. $\ddagger$ Elevated distress level $=>1 \mathrm{SD}$ or $>2 \mathrm{SD}$. 
TABLE 3. Results of structural brain magnetic resonance imaging for 54 adolescents and young adults after neonatal ASO

\begin{tabular}{|c|c|c|c|c|c|c|c|c|}
\hline \multirow[b]{2}{*}{ Classification criteria } & \multicolumn{3}{|c|}{ Reduced brain volume* } & \multicolumn{3}{|c|}{ White matter injury } & \multirow[b]{2}{*}{ Encephalomalacia } & \multirow{2}{*}{$\begin{array}{l}\text { Additional } \\
\text { abnormality }\end{array}$} \\
\hline & Intrinsic & Extrinsic & Total & PVL & Non-periventricular & Total & & \\
\hline No abnormality (grade 0 ) & $43(79.6)$ & $50(92.6)$ & $41(75.9)$ & $27(50.0)$ & $44(81.5)$ & $23(42.6)$ & $51(94.4)$ & 0 \\
\hline Total abnormality & $11(20.4)$ & $4(7.4)$ & $13(24.1)$ & $27(50.0)$ & $10(18.5)$ & $31(57.4)$ & $3(5.6)$ & 0 \\
\hline Mild (grade 1) & $6(11.1)$ & $3(5.6)$ & & $18(33.0)$ & $6(11.1)$ & & & \\
\hline Moderate (grade 2) & $2(3.7)$ & $1(1.8)$ & & $7(13.3)$ & $2(3.7)$ & & & \\
\hline Severe (grade 3) & $3(5.6)$ & 0 & & $2(3.7)$ & $2(3.7)$ & & & \\
\hline
\end{tabular}

Data presented as n (\%). PVL, Periventricular leukomalacia. *Extrinsic brain volume loss refers to widening of the sulci; intrinsic volume loss refers to widening of the ventricles.

Mann-Whitney $U$ test was used. The Wilcoxon rank sum test and correlation analyses (Spearman's correlation coefficient [SP]) were used to analyze the continuous variables. To study the effect of the risk factors on the neurodevelopmental outcome parameters, multivariate analysis was applied, using multiple regression models. The considered risk factors were statistically significant on the corresponding univariate analysis and had been selected using a stepwise selection procedure (R.M.).

Statistical analysis was performed using the Statistical Package for Social Sciences, for Windows, version 17.0 (SPSS GmbH Software, Munich, Germany). All statistical tests were performed at a significance level of $P=.05$.

\section{RESULTS}

\section{Neurologic Status}

Neurologic status was normal in $90 \%$ (grade $0, \mathrm{n}=54$ ) and impaired in $10 \%(\mathrm{n}=6)$. Of the 6 patients with neurologic abnormalities, 2 had moderate impairment (grade 1, $3.3 \%$ ). Of these 2 patients, 1 had developed motor dyspraxia and 1 required a ventriculoperitoneal shunt after perioperative intracerebral hemorrhage and permanent hydrocephalus. The other 4 patients $(6.7 \%)$ had severe neurologic dysfunction (grade 2); 2 had spastic hemiplegia and 2, spastic tetraplegia. Motor dyspraxia was noted in 7 patients $(11.7 \%)$, and dysfunction of the cranial nerves (impairment of tongue movement) was noted in 2 patients $(3.3 \%)$. Finally, 6 patients $(8.3 \%)$ had ataxia, and 2 had presented with dysreflexia $(3.3 \%)$. Neither seizures nor sensory dysfunction or abnormal head shape and growth had manifested.

\section{Psycho-Intellectual Outcome}

Intelligence. The average full-scale, verbal, and performance IQs were not reduced compared with the population norms (Table 2). The frequency of scores $>1$ SD or $>2$ SD less than the expected mean (ie, $\leq 85$ or $\leq 70$; expected frequency $16 \%$ or $2 \%$ ) was $14 \%$ and $11 \%$ for the performance IQ, respectively.

Analytical thinking. A score greater than the expected mean for subtest 3 of the Leistungsprüfsytem nach Horn had a mean percentage of $86 \%$ (range, $18 \%-98 \%$; Table 2 ). Orthography. The average orthographic performance was significantly reduced in 4 of the 6 subtests and in the summary range MRT score compared with the population norms. In all 6 subtests, the frequency of a percentage $>1$
SD or $>2$ SD less than the expected frequency of $16 \%$ and $2 \%$, respectively, was increased (Table 2).

Psychological condition. The average Global Severity Index T score indicated a significantly reduced psychological distress level compared with the norm (Table 2). More than two thirds of our patients estimated their psychological condition within the normal range of $\pm 1 \mathrm{SD}$, and $25 \%$ scored better than expected $(<1 \mathrm{SD})$.

\section{Structural Brain Imaging}

The incidence and distribution of the classified criteria with respect to structural abnormalities found on brain MRI are listed in Table 3. Of the 60 patients, $50 \%$ had PVL, two thirds of which were rated as mild. The incidence of non-periventricular white matter lesions was $18.5 \%$, for a total incidence of white matter injury of $57.4 \%$. A reduced brain volume was seen in $24.1 \%$, most of which was rated as mild. Finally, 3 patients $(5.6 \%)$ presented with a substance defect related to a focal remote cerebral infarction. Examples are shown in Figure 1.

For the tMRI score, 37 patients $(68.5 \%)$ were rated as having no or a mild abnormality (grade 0$), 10(18.5 \%)$ as moderate (grade 1), and $7(13 \%)$ as having severe abnormalities (grade 2).

\section{Univariate Associations Among Outcome Parameters}

The grade of neurologic dysfunction correlated significantly with a poorer outcome for the verbal, performance, and full-scale IQ, analytical thinking, and orthographic performance. A reduced brain volume correlated with poorer average IQ scores, and the grade of the tMRI score correlated inversely with the scores of intellectual outcome (Table 4). Intertest correlations were found between the MRT summary range and the verbal IQ (SP, 0.611; $P<.0001$ ), performance IQ (SP, 0.646; $P<.0001$ ), fullscale IQ (SP, $0.698 ; P<.0001$ ), and analytical thinking (SP, $0.511 ; P<.0001)$ scores.

Regarding the associations between neurologic status and abnormalities on brain MRI, a weak correlation was found between the grade of focal white matter injury and grade of neurologic dysfunction (SP, $0.285, P=.037$ ). Of the $68.5 \%$ of patients with absent or mild brain MRI 

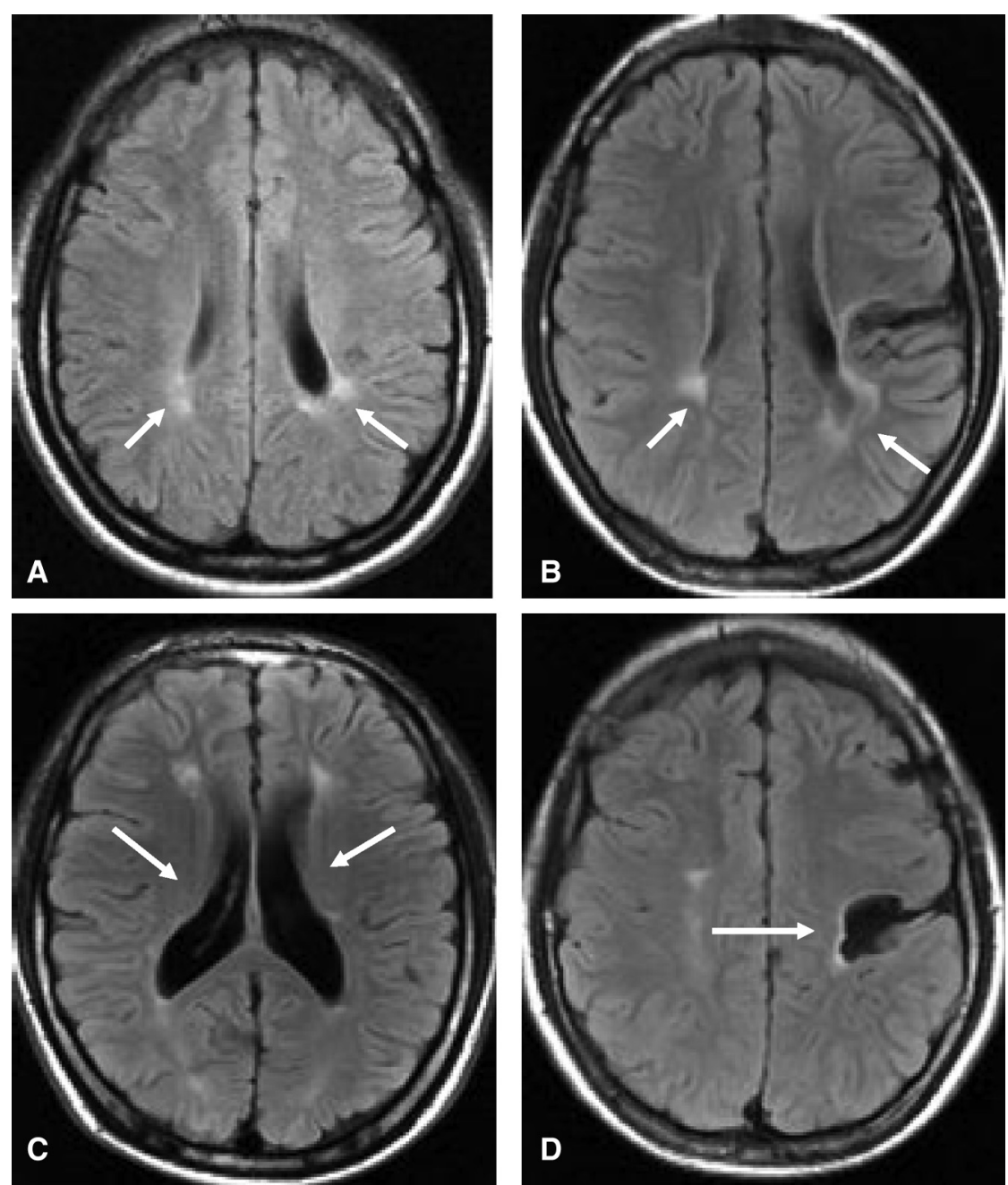

FIGURE 1. Examples of structural brain magnetic resonance imaging abnormalities in adolescents and young adults after neonatal arterial switch operation (T2-weighted axial planes). A, Moderate periventricular leukomalacia (arrows). B, Severe periventricular leukomalacia (arrows). C, Severe intrinsic volume loss with ventricular dilatation (arrows), mild extrinsic volume loss with increased width of sulci, and moderate periventricular leukomalacia. $\mathrm{D}$, Substance defect of the left central gyrus (arrow) and non-periventricular white matter injury.

abnormalities (tMRI grade 0), 92\% presented without neurologic dysfunction. Also, of the patients without neurologic dysfunction, $70 \%$ did not show any significant structural brain abnormality (tMRI grade 0 ). Thus, a correspondence between the grade of neurologic dysfunction and brain MRI status was present in more than two thirds (68\%) of the patient group. In contrast, the neurologic status was worse than the brain MRI result in $6 \%$, and the MRI result was classified as worse than the neurologic status in $26 \%$.

\section{Multivariate Risk Factor Analysis for Outcome Parameters}

In the multivariate analysis model, 6 dependent outcome parameters were considered, each related to 9 risk factors (Table 5). Of those, the model was able to confirm 2 variables as independent risk factors for neurodevelopmental outcome and structural brain MRI status. Severe preoperative acidosis and hypoxia were the only independent risk factors for neurologic dysfunction, with reduced brain volume and focal white matter injury on MRI also predicting a risk of a reduced full-scale IQ. Poor socioeconomic status was also an independent risk factor for a reduced fullscale IQ and for reduced orthographic performance. The considered risk factors concerning CPB modality and perioperative and postoperative complications did not independently influence any of the outcome parameters.

\section{DISCUSSION}

Children with congenital heart disease who undergo surgery with $\mathrm{CPB}$ as neonates or infants remain at an increased risk of neurodevelopmental and psychosocial dysfunction in childhood and continuing into adolescence. ${ }^{12-14}$ The 
TABLE 4. Significant correlations between developmental test results and neurologic dysfunction or structural brain MRI abnormalities

\begin{tabular}{|c|c|c|c|c|c|c|c|c|}
\hline \multirow[b]{2}{*}{ Test } & \multicolumn{2}{|c|}{$\begin{array}{c}\text { Neurologic } \\
\text { dysfunction (grade 0-2) }\end{array}$} & \multicolumn{2}{|c|}{$\begin{array}{c}\text { Reduced brain } \\
\text { volume (grade 0-3) }\end{array}$} & \multicolumn{2}{|c|}{$\begin{array}{c}\text { Focal white matter } \\
\text { injury (grade 0-3) }\end{array}$} & \multicolumn{2}{|c|}{$\begin{array}{l}\text { tMRI score } \\
\text { (grade 0-2) } \\
\end{array}$} \\
\hline & SP & $P$ value & SP & $P$ value & SP & $P$ value & SP & $P$ value \\
\hline HAWIE-R $^{8}$ & & & & & - & - & & \\
\hline Verbal IQ & -0.323 & .015 & -0.318 & .020 & & & & \\
\hline Performance IQ & -0.473 & $<.0001$ & -0.307 & .025 & & & & \\
\hline Full scale IQ & -0.443 & .001 & -0.358 & .009 & & & -0.282 & .041 \\
\hline $\operatorname{LPS}^{9}$ & & & - & - & - & - & & \\
\hline Analytical thinking & -0.443 & .001 & & & & & -0.29 & .035 \\
\hline $\mathrm{MRT}^{10}$ & & & - & - & - & - & & \\
\hline Lengthening & -0.392 & .003 & & & & & & \\
\hline Shortening & -0.305 & .022 & & & & & & \\
\hline Confusion of consonants & -0.304 & .023 & & & & & & \\
\hline Confusion of vowels & -0.307 & .009 & & & & & & \\
\hline $\begin{array}{l}\text { Capitalization, separate, compound } \\
\text { writing }\end{array}$ & & & & & & & -0.288 & .037 \\
\hline Foreign words & -0.285 & .033 & & & & & & \\
\hline Orthography summary range & -0.344 & .010 & & & & & & \\
\hline
\end{tabular}

$t M R I$, Total structural brain magnetic resonance imaging; $S P$, Spearman's correlation coefficient; HAWIE-R, Hamburg-Wechsler intelligence test, revised; $I Q$, intelligence quotient; $L P S$, Leistungsprüfsystem nach Horn; MRT, Mannheimer Rechtschreib test.

more we are convinced that "caring for the adolescent with surgically repaired d-transposition of the great arteries can be one of the most satisfying experiences in congenital cardiology," ${ }^{15}$ the more we should be following up the neurologic and psychosocial outcomes in adolescent and young adult patients. In addition to the Boston Circulatory Arrest Study cohort, ${ }^{1}$ the Aachen TGA study cohort represents another homogeneous patient group in which the long-term neurodevelopmental outcomes and the potential risk factors have been periodically evaluated. ${ }^{2,4,6}$ In the present study, we report our follow-up data at a mean patient age of 17 years for a representative, unselected cohort. The diagnostic tool of MRI for brain examination has become more and more established. Thus, we sought to focus on the relations between the neurodevelopmental outcomes and alterations found on structural brain imaging, because very few data are yet available in this area of interest. ${ }^{1,16}$

\section{Neurologic Status}

It is well known that the neonatal ASO can be associated with increased neurologic impairment in childhood. ${ }^{17-21}$ The earlier evaluation of our study group demonstrated marked impairment of clinical neurologic status in $9 \%$ of our patient at 5 years of age, ${ }^{2}$ increasing to $27 \%$ at 10 years

TABLE 5. Multivariate regression analysis between cerebral risk factors and neurodevelopmental outcomes

\begin{tabular}{|c|c|c|c|c|c|c|c|c|c|c|c|c|}
\hline \multirow[b]{3}{*}{ Risk factor } & \multicolumn{12}{|c|}{ Outcome parameters } \\
\hline & \multicolumn{2}{|c|}{$\begin{array}{l}\text { Neurologic } \\
\text { dysfunction }\end{array}$} & \multicolumn{2}{|c|}{$\begin{array}{c}\text { Reduced } \\
\text { brain volume }\end{array}$} & \multicolumn{2}{|c|}{$\begin{array}{l}\text { Focal white } \\
\text { matter injury }\end{array}$} & \multicolumn{2}{|c|}{ tMRI score } & \multicolumn{2}{|c|}{ Full scale IQ } & \multicolumn{2}{|c|}{$\begin{array}{c}\text { Orthography } \\
\text { summary range }\end{array}$} \\
\hline & $\mathbf{R}^{2}$ & $P$ value & $\mathbf{R}^{2}$ & $P$ value & $\mathbf{R}^{2}$ & $P$ value & $\mathbf{R}^{2}$ & $P$ value & $\mathbf{R}^{2}$ & $P$ value & $\mathbf{R}^{2}$ & $P$ value \\
\hline $\begin{array}{l}\text { Severe preoperative acidosis and } \\
\text { hypoxia }\end{array}$ & 0.3701 & $<.0001 *$ & 0.2241 & $.0457 *$ & 0.2788 & $.0446 *$ & 0.2709 & .0512 & 0.513 & $.011^{*}$ & 0.394 & $>.2$ \\
\hline Temperature at DHCA initiation & 0.3701 & $>.2$ & 0.2241 & $>.2$ & 0.2788 & .1279 & 0.2709 & $>.2$ & 0.513 & $>.2$ & 0.394 & $>.2$ \\
\hline DHCA duration & 0.3701 & $>.2$ & 0.2241 & $>.2$ & 0.2788 & $>.2$ & 0.2709 & $>.2$ & 0.513 & .174 & 0.394 & $>.2$ \\
\hline CPB duration & 0.3701 & $>.2$ & 0.2241 & $>.2$ & 0.2788 & $>.2$ & 0.2709 & $>.2$ & 0.513 & $>.2$ & 0.394 & $>.2$ \\
\hline $\begin{array}{l}\text { Perioperative and postoperative } \\
\text { cardiocirculatory insufficiency }\end{array}$ & 0.3701 & $>.2$ & 0.2241 & $>.2$ & 0.2788 & $>.2$ & 0.2709 & $>.2$ & 0.513 & $>.2$ & 0.394 & $>.2$ \\
\hline $\begin{array}{l}\text { Perioperative and postoperative } \\
\text { resuscitation events }\end{array}$ & 0.3701 & .1208 & 0.2241 & $>.2$ & 0.2788 & $>.2$ & 0.2709 & .1495 & 0.513 & $>.2$ & 0.394 & $>.2$ \\
\hline Postoperative IVH & 0.3701 & $>.2$ & 0.2241 & $>.2$ & 0.2788 & .1463 & 0.2709 & $>.2$ & 0.513 & $>.2$ & 0.394 & $>.2$ \\
\hline $\begin{array}{l}\text { Perioperative and postoperative } \\
\text { seizures }\end{array}$ & 0.3701 & $>.8$ & 0.2241 & $>.2$ & 0.2788 & .1715 & 0.2709 & $>.2$ & 0.513 & $>.2$ & 0.394 & $>.2$ \\
\hline Socioeconomic status & 0.3701 & $>.2$ & 0.2241 & $>.2$ & 0.2788 & $>.2$ & 0.2709 & $>.2$ & 0.513 & $<.0001^{*}$ & 0.394 & $<.0001^{*}$ \\
\hline
\end{tabular}


of age. ${ }^{6}$ The rate of dysfunction has decreased to $10 \%$ with moderate or severe impairment in the present study, presumably owing to improvement of the milder forms of neurologic abnormality from special education and physical therapy. Higher grades of neurologic dysfunction, such as those present in patients with palsy or organic motor coordination disorders, however, will persist for the patient's lifetime, despite adequate therapy. Because we have observed the whole patient cohort for $>2$ decades, we believe that the percentage of moderate to severe neurologic dysfunction we found is sufficiently reliable and was not markedly biased by nonparticipating patients without neurologic deficits. The occurrence of embolic events to the brain due to balloon atrioseptostomy as a cause of severe neurologic injury ${ }^{22}$ has been controversial. ${ }^{23}$ However, we could not determine whether this had occurred in our patients because brain imaging in the neonatal age had not been performed. The clinical relevance of our findings is underlined by the significant correlation between reduced intelligence and poor orthography results. Confirming our multivariate risk factor analysis from our corresponding study at age 10 years, ${ }^{6}$ we found the presence of severe preoperative acidosis and hypoxia to be the only independent predictive factor for neurologic dysfunction. In contrast, procedure-related factors as CPB and circulatory arrest times and postoperative cardiocirculatory insufficiency did not reach statistical significance.

\section{Intellectual Outcome}

Although the mean scores of formal intelligence were not lower than expected, the SDs were larger, suggesting widespread variability among our patients. Moreover, the performance IQs showed considerably increased rates of patients at $<2$ SDs $(11 \%)$. Compared with our studies at a mean age of 5 and 10 years, ${ }^{2,6}$ the mean values of the intelligence parameters were stable; however, the SDs had markedly increased. This points to a greater incidence of particular cognitive deficits in young patients after neonatal ASO compared with the normal population, confirming the recent poor results of a neuropsychological evaluation from the Boston study group. ${ }^{1}$ That executive, acquired functions, in particular, have been found to be reduced can be underlined by the observation that our patients had a considerable reduction in their orthographic skills but not analytical thinking, which is a part of the fluid, inborn intelligence. Functional disabilities, generally known as a comorbidity of complex congenital heart defects during childhood, ${ }^{12,24,25}$ will persist into adolescence and young adulthood in patients after neonatal ASO, most of whom have grown up the same as healthy children, without severe cardiac or extracardiac problems, but with a history of fetal reduction of brain oxygenation ${ }^{26,27}$ and delayed brain maturation. ${ }^{28-30}$ The practical effect of our results has been reflected by the increased rate of attendance to special schools and the lack of the final school examination.

Consistent with our previous assessment, ${ }^{6}$ reduced intelligence and orthographic performance were associated with neurologic impairment. Preoperative acidosis and hypoxia was again the only independent patient-related risk factor for a reduced IQ. Poorer socioeconomic status as an independent risk factor for reduced intelligence and orthography performance has been well proved ${ }^{31}$ and has been underlined by our data.

\section{Psychological Condition}

As a part of health-related quality of life, the effect of the subjective psychological condition on the daily lives of young patients after neonatal ASO has been of increasing significance. Our patients perceived lower psychological distress than the population norms, and none of them had received psychotherapy or psychiatric medication. This was even more remarkable because, at 10 years of age, ${ }^{4}$ their parents had reported increased psychological stress, in projection, for their children. It is well known that the parents of children with congenital heart disease often have an overcautious parenting style. ${ }^{32,33}$ However, the self-reported social cognition of the adolescents was worse in the Boston study group with respect to positive emotions and autistic traits compared with the reference population. ${ }^{1}$ Our present data do not support the assumption that adolescents with congenital heart disease will have an increased risk of social cognition deficits, although this had been assumed (related by the parents) in both study groups at ages 8 years ${ }^{34}$ and 10 years. ${ }^{4}$ That the patients themselves, even if significantly handicapped, can report a positive subjective psychological condition, in contrast to their caregivers, is well reputed and results from successful coping styles. $^{4,32,33}$ Recently, it has been hypothesized that young adults with even severe congenital heart disease can develop a stronger "sense of coherence" than do healthy counterparts, leading them to accept life "as it is." ${ }^{35}$ Nevertheless, careful surveillance and ongoing prevention to minimize the risk of psychological distress are indicated for young patients after neonatal ASO.

\section{Structural Brain MRI}

Since the 1990s, neurodevelopmental impairment after neonatal and infant cardiac surgery for complex congenital heart disease has been systematically detected. The factors of perioperative management, including CPB modality, had been assumed to be the main potential independent risk factors. During the past 10 years, cerebral morphologic and functional abnormalities, assessed using MRI, have come into interest.

Recent research has focused on defining the effect of congenital heart disease on fetal and infant brain development, postnatal preoperative and postoperative brain injury, 
and possible consecutive neurologic and developmental dysfunction. Current MRI studies have suggested that term neonates and even third-trimester fetuses with congenital heart disease will have delayed brain maturation and increased vulnerability to hypoxic injury in the preoperative and postoperative course. ${ }^{13,22,23,28-30,36-45}$ Our patients, born in the late 1980s and early 1990s, who had not undergone systematic brain imaging as neonates, presented with increased structural MRI abnormalities, compared with that expected for the normal population. This was underlined by the recent results for a control group of 41 healthy age-matched volunteers aged 11 to 17 years. ${ }^{16}$ Two thirds of our patients had focal white matter injury, one quarter had a reduced brain volume, and 5\% had marked encephalomalacia. Compared with a group of premature, very-low-birth-weight infants, who have been described at the greatest risk of PVL $(3 \%-4 \%$ of infants weighing $<1500 \mathrm{~g}[3.3 \mathrm{lb}]$ and $4 \%-10 \%$ of those born at $<33$ weeks of gestation will have PVL), ${ }^{46}$ the rate was significantly greater in our cohort.

Of our patients, one third was rated as having significant moderate or severe abnormalities, confirming the recent rates from the Boston study group at 16 years of age after ASO. ${ }^{1}$ In our study, focal white matter injury found on structural MRI was even more frequent. One possible explanation might lie in the types of sequences used. We used a 3T magnet with fluid attenuated inversion recovery sequences (with the greatest sensitivity for white matter lesions). However, in the Boston study, a 1.5T magnet with dual echo was used. These sequences might not have detected the subtle periventricular white matter injuries. In the Boston study, ${ }^{1}$ no significant associations between the structural MRI abnormalities and the patients' neurodevelopmental disability were detected. In a subsequent report, however, the Boston investigators ${ }^{47}$ used diffusion tensor imaging, which is very well suited to assessing the integrity of the white matter tracts. In that study, they demonstrated a very high incidence of white matter microstructural abnormalities, mainly multifocal punctate hypodensities suggestive of mineralization. ${ }^{47}$ They speculated that it might have been related to the reported neurocognitive deficits. ${ }^{47}$ In our cohort, we only used T2 gradient echo sequences to specifically search for areas of susceptibility differences that would be present in the case of hemorrhage or mineralization, and we did not find these lesions. Such lesion might have remained unnoticed on a gradient echo sequence.

In an additional study, predominant white matter abnormalities suggestive of a hypoxic-ischemic origin and increased neurodevelopmental impairment were described in adolescents with corrected congenital heart disease in infancy, including 10 patients after ASO ${ }^{16}$ Recently, in a study investigating the nature, timing, and consequences of brain injury on MRI in 153 young infants undergoing cardiac surgery with and without $\mathrm{CPB},{ }^{45}$ white matter injury was confirmed as the most prevalent abnormality. Its rate was associated with the degree of brain immaturity before surgery and had increased after surgery, independent of the use of $\mathrm{CPB} .{ }^{45}$ Instead, the rate was related to the diagnostic group and the use of circulatory arrest. ${ }^{45} \mathrm{It}$ is notable that the neurodevelopmental outcome at 2 years of age was related to brain immaturity rather than to white matter injury. In neonates with TGA, brief DHCA was not associated with an increased risk of white matter injury on MRI 1 week after ASO ${ }^{48}$ In the intrauterine TGA physiology, relative cerebral hypoxia will be caused by preferential blood flow, with a markedly reduced oxygen content from the right ventricle by way of the ascending aorta into the brain arteries. This will lead to the so-called brain sparing effect with cerebral vasodilatation, bearing the risk of delayed structural and functional brain maturation ${ }^{13,44}$ and its potential implications, including a predilection for additional hypoxic or ischemic injury in the pre- and postnatal periods.

In our study, the grade of white matter injury correlated with the grade of neurologic dysfunction. In contrast, just as in the Boston study, ${ }^{1}$ a significant association with any of the test results of developmental outcome could not be evaluated. A reduced brain volume and poorer tMRI score, however, correlated moderately with reduced average IQ, analytical thinking, and orthography scores. Summarizing the associations between the structural brain MRI abnormalities and neurodevelopmental outcomes, we found a high specificity of $92 \%$ with respect to the MRI findings confirming normal neurologic function. However, the sensitivity for MRI to identify neurologic dysfunction was moderate at $68 \%$. A satisfactory rate of predictive power was only given for severe neurologic impairment.

\section{Risk Factor Analysis}

Consistent with the findings from our previous studies, ${ }^{4,6}$ preoperative acidosis and hypoxia was an independent risk factor for later poor outcomes. Because of the presumed prenatally acquired disposition for an increased risk of postnatal hypoxic or ischemic injury to the brain of cyanotic neonates with TGA, the significant associations between this parameter and the discussed abnormalities found by structural brain MRI (eg, reduced brain volume and focal white matter injury) and neurologic dysfunction were not unexpected.

However, the parameters of perioperative management could not be confirmed as independent risk factors, although the use of low flow CPB includes a risk of cerebral embolic injury, cerebral hypoperfusion, and an inflammatory response, and hypothermia can cause a loss of cerebral autoregulation and increase the risk of cerebral hypoxia, leading to strokes or seizures. Consistent with our previous studies, ${ }^{2,4,6}$ the DHCA duration was not a significant risk factor. This is in line with the results from the Boston 
TGA study, in which, at age 16 years, no significant differences were found between patients in the low-flow CPB group and those in the circulatory arrest group. ${ }^{1}$ Using the $\mathrm{pH}$-stat management in our patients, perioperative seizures were rare and did not influence any of the outcome parameters, nor did any postoperative management factors, such as cardiocirculatory insufficiency or resuscitation events. Socioeconomic status was confirmed as a wellknown independent risk factor for worsened intelligence and orthographic performance. Summarizing our multivariate risk factor analysis, the results of the present study have underlined the increasing published data suggesting that most risk factors for neurodevelopmental and neuropsychological outcomes after neonatal and infant heart surgery for complex congenital heart disease will be patient-related or socioeconomic, with only a few procedure-related and potentially modifiable. ${ }^{31}$

\section{Study Limitations}

The present study was a single-center, long-term followup study with a moderate, but persistent, number of patients, treated in the 1980s and early 1990s using DHCA and before the era of prenatal diagnosis of the heart defect. Our results might not be transferable to neonates born with TGA today. The outcomes were discussed irrespective of the metabolic or functional brain MRI data obtained, which will be reported separately.

\section{CONCLUSIONS}

Despite the encouraging clinical neurodevelopmental outcomes in most adolescents and young adults after neonatal ASO, a considerable minority will have performances less than the expected level and will require ongoing surveillance, therapeutic intervention, and rehabilitation. Considering the high frequency of structural brain abnormalities on MRI, prospective multicenter studies are needed to investigate prospectively and periodically, from fetal to adult life, the relations among the structural, metabolic, and functional brain MRI phenomena, clinical risk factors, and standardized neurocognitive and psychosocial outcome parameters. These studies are needed to define the prognostic patterns for patients at special neurodevelopmental risk.

\section{References}

1. Bellinger DC, Wypij D, Rivkin MJ, de Maso DR, Robertson RL Jr, DunbarMasterson C, et al. Adolescents with d-transposition of the great arteries corrected with arterial switch procedure: neuropsychological assessment and structural brain imaging. Circulation. 2011;124:1361-9.

2. Hoevels-Guerich HH, Seghaye MC, Daebritz S, Messmer BJ, von Bernuth G. Cognitive and motor development in preschool and school-aged children after neonatal arterial switch operation. J Thorac Cardiovasc Surg. 1997;114:578-85.

3. Hoevels-Guerich HH, Seghaye MC, Daebritz S, Messmer BJ, von Bernuth G. Cardiological and general health status in preschool- and school-aged children after neonatal arterial switch operation. Eur J Cardiothorac Surg. 1997;12: 593-601.
4. Hoevels-Guerich HH, Konrad K, Wiesner M, Minkenberg R, HerpertzDahlmann B, Messmer BJ, et al. Long-term behavioural outcome after neonatal arterial switch operation for transposition of the great arteries. Arch Dis Child. 2002; $87: 506-10$.

5. Hoevels-Guerich HH, Seghaye MC, Ma Q, Miskova M, Messmer BJ, von Bernuth G. Long-term results of cardiological and general health status in children after neonatal arterial switch operation. Ann Thorac Surg. 2003;75: 935-43.

6. Hoevels-Guerich HH, Seghaye MC, Schnitker R, Wiesner M, Huber W, Minkenberg R, et al. Long-term neurodevelopmental outcomes in school-aged children after neonatal arterial switch operation. J Thorac Cardiovasc Surg. 2002; $124: 448-58$.

7. Moore H, Kleining G. Das soziale Selbstbild der Gesellschaftsschichten in Deutschland. Kölner Zeitschrift für Soziologie und Sozialpsychologie. 1968; 20:86-119.

8. Tewes U. Hamburg-Wechsler-Intelligenztest für Erwachsene (Revision 1991). Bern: Verlag Hans Huber; 1994.

9. Horn W. L-P-S Leistungsprüfsystem. 2nd ed. Göttingen, Germany: Hogrefe; 1983.

10. Jaeger RS, Jundt E. Mannheimer Rechtschreib-Test: Langform und Halbformen. 2nd ed. Göttingen, Germany: Verlag für Psychologie C. J. Hogrefe; 1981.

11. Franke G.H. SCL-90-R. Die Symptom-Check-Liste von Derogatis. Deutsche Version. Beltz Test, Weinheim, Germany, 1995.

12. Marino BS, Lipkin PH, Newburger JW, Peacock G, Gerdes M, Gaynor JW, et al. Neurodevelopmental outcomes in children with congenital heart disease: evaluation and management: a scientific statement from the American Heart Association. Circulation. 2012;126:1143-72.

13. Herberg U, Hövels-Gürich H. Neurological and psychomotor development of foetuses and children with congenital heart disease-causes and prevalence of disorder and long-term prognosis. Z Geburtshilfe Neonatol. 2012;216: $132-40$.

14. Hövels-Gürich HH. Psychomotor development of children with congenital heart defects: causes, prevalence and prevention of developmental disorders after cardiac surgery in childhood. Monatsschr Kinderheilkd. 2012;160:118-28.

15. Mahle WT. Boston circulatory arrest study at 16 years: handing over the keys. Circulation. 2011;124:1319-20.

16. Von Rhein M, Scheer I, Loenneker T, Huber R, Knirsch W, Latal B. Structural brain lesions in adolescents with congenital heart disease. J Pediatr. 2011;158: 984-9.

17. Bellinger DC, Wypij D, Kuban KCK, Rappaport LA, Hickey PR, Wernovsky G, et al. Developmental and neurological status of children at 4 year of age after heart surgery with hypothermic circulatory arrest or low-flow cardiopulmonary bypass. Circulation. 1999;100:526-32.

18. Ellerbeck KA, Smith ML, Holden EW, McMenamin SC, Badawi MA, Brenner JI. Neurodevelopmental outcome in children surviving d-transposition of the great arteries. J Dev Behav Pediatr. 1998;19:335-41.

19. Hoevels-Guerich HH, Seghaye MC, Sigler M, Kotlarek F, Bartl A, Neuser J, et al. Neurodevelopmental outcome related to cerebral risk factors in children after neonatal arterial switch operation. Ann Thorac Surg. 2001;71:881-8.

20. Karl TR, Hall S, Ford G, Kelly EA, Brizard CPR, Mee RBB, et al. Arterial switch with full-flow cardiopulmonary bypass and limited circulatory arrest: neurodevelopmental outcome. J Thorac Cardiovasc Surg. 2004;127:213-22.

21. Bellinger DC, Wypij D, du Plessis AJ, Rappaport LA, Jonas RA, Wernovsky G, et al. Neurodevelopmental status at eight years in children with dextrotransposition if the great arteries: the Boston Circulatory Arrest Trial. J Thorac Cardiovasc Surg. 2003;126:1385-96.

22. McQuillen PS, Hamrick SE, Perez MJ, Barkovick AJ, Glidden DV, Karl TR, et al. Balloon atrial septostomy is associated with preoperative stroke in neonatal with transposition of the great arteries. Circulation. 2006;113:280-5.

23. Petit CJ, Rome JJ, Wernovsky G, Mason SE, Shera DM, Nicolson SC, et al. Preoperative brain injury in transposition of the great arteries is associated with oxygenation and time to surgery, not balloon atrial septostomy. Circulation. 2009;119:709-16.

24. Majnemer A, Limperopoulos C, Shevell M, Rohlicek C, Rosenblatt B, Tchervenkov C. Developmental and functional outcomes at school entry in children with congenital heart defects. J Pediatr. 2008;153:55-60.

25. Van der Rijken R. Neurocognitive Effects of Open-Heart Surgery in School-Age Children with Congenital Heart Disease. Nijmegen, The Netherlands: Proefschrift Radboud Universiteit; 2010.

26. Modena A, Horan C, Visintine J, Chanthasenanont A, Wood D, Weiner S. Fetuses with congenital heart disease demonstrate signs of decreased cerebral impedance. Am J Obstet Gynecol. 2006;195:706-10. 
27. Berg C, Gembruch O, Gembruch U, Geipel A. Doppler indices of the middle cerebral artery in fetuses with cardiac defects theoretically associated with impaired cerebral oxygen delivery in utero: is there a brain-sparing effect? Ultrasound Obstet Gynecol. 2009;34:666-72.

28. Miller SP, McQuillen PS, Hamrick S, Xu D, Glidden DV, Charlton N. Abnormal brain development in newborns with congenital heart disease. $N$ Engl J Med. 2007;357:1928-38.

29. Licht DJ, Shera DM, Clancy RR, Wernovsky G, Montenegro LM, Nicolson SC, et al. Brain maturation is delayed in infants with complex congenital heart defects. J Thorac Cardiovasc Surg. 2009;137:529-36.

30. Limperopoulos C, Tworetzky W, McElhinney DB, Newburger JW, Brown DW, Robertson RL Jr, et al. Brain volume and metabolism in fetuses with congenital heart disease: evaluation with quantitative magnetic resonance imaging and spectroscopy. Circulation. 2010;121:26-33.

31. Tabbutt S, Gaynor JW, Newburger JW. Neurodevelopmental outcomes after congenital heart surgery and strategies for improvement. Curr Opin Cardiol. 2012;27:82-91.

32. Latal B, Helfricht S, Fischer JE, Bauersfeld U, Landolt MA. Psychological adjustment and quality of life in children and adolescents following open-heart surgery for congenital heart disease: a systematic review. BMC Pediatr. 2009; 9:6.

33. Spijkerboer AW, Helbing WA, Bogeers AJJD, Van Domburg RT, Verhulst FC, Utens EMWJ. Long-term psychological distress and styles of coping, in parents of children and adolescents who underwent invasive treatment for congenital cardiac disease. Cardiol Young. 2007;17:638-45.

34. Bellinger DC, Newburger JW, Wypij D, Kuban KC, du Plessis AJ, Rappaport LA. Behaviour at eight years in children with surgically corrected transposition: the Boston Circulatory Arrest Trial. Cardiol Young. 2009;19:86-97.

35. Moons P. Patient-reported outcomes in congenital cardiac disease: Are they as good as you think they are? Cardiol Young. 2010;20:143-8.

36. McQuillen PS, Barkovich AJ, Hamrick SE, Perez M, Ward P, Glidden DV, et al. Temporal and anatomic risk profile of brain injury with neonatal repair of congenital heart defects. Stroke. 2007;38:736-41.

37. McQuillen PS, Miller SP. Congenital heart disease and brain development. Ann N Y Acad Sci. 2010;1184:68-86.
38. Miller SP, McQuillen PS, Vigneron DB, Glidden DV, Barkovich AJ Ferriero DM, et al. Preoperative brain injury in newborns with transposition of the great arteries. Ann Thorac Surg. 2004;77:1698-706.

39. Mahle WT, Tavani F, Zimmerman RA, Nicolson SC, Galli KK, Gaynor JW, et al An MRI study of neurological injury before and after congenital heart surgery. Circulation. 2002;106:1109-14.

40. Galli KK, Zimmermann RA, Jarvik GP, Wernovsky G, Kuypers MK, Clancy RR, et al. Periventricular leukomalacia is common after neonatal cardiac surgery. J Thorac Cardiovasc Surg. 2004;127:692-704.

41. Park IS, Yoon SY, Min JY, Kim YH, Ko JK, Kim KS, et al. Metabolic alterations and neurodevelopmental outcome of infants with transposition of the great arteries. Pediatr Cardiol. 2006;27:569-76.

42. Licht DJ, Wang J, Silvestre DW, Nicolson SC, Montenegro LM, Wernovsky G, et al. Preoperative cerebral blood flow is diminished in neonates with severe congenital heart defects. J Thorac Cardiovasc Surg. 2004;128:841-9.

43. Andropoulos DB, Hunter JV, Nelson DP, Stayer SA, Stark AR, McKanzie ED Brain immaturity is associated with brain injury before and after neonatal cardiac surgery with high-flow bypass and cerebral oxygenation monitoring. $J$ Thorac Cardiovasc Surg. 2010;139:543-56.

44. Donofrio MT, Massaro AN. Impact of congenital heart disease on brain development and neurodevelopmental outcome. Int J Pediatr. 2010;2010.

45. Beca J, Gunn JK, Coleman L, Hope A, Reed PW, Hunt RW, et al. New white matter brain injury after infant heart surgery is associated with diagnostic group and the use of circulatory arrest. Circulation. 2013;127:971-9.

46. Rezaie P, Dean A. Periventricular leukomalacia, inflammation and white mat ter lesions within the developing nervous system. Neuropathology. 2002;2: 106-32.

47. Rivkin MJ, Watson CG, Scoppettuolo LA, Wypij D, Vajapeyam S, Bellinger DC, et al. Adolescents with d-transposition of the great arteries repaired in early infancy demonstrate reduced white matter microstructure associated with clinical risk factors. J Thorac Cardiovasc Surg. 2013;146:543-9.

48. Drury PP, Gunn AJ, Bennet L, Ganeshalingham A, Finucane K, Buckley D, et al. Deep hypothermic circulatory arrest during the arterial switch operation is associated with reduction in cerebral oxygen extraction but no increase in white matter injury. J Thorac Cardiovasc Surg. 2013;146:1327-33.

\title{
EDITORIAL COMMENTARY
}

\section{Leaving the nest: Facing adulthood after the arterial switch operation}

\author{
Frank A. Pigula, MD
}

See related article on pages 2190-9.

The report in this issue of the Journal by Heinrichs and colleagues ${ }^{1}$ from Aachen is an important companion study

\footnotetext{
From the Department of Cardiothoracic Surgery, Children's Hospital of Boston, Boston, Mass.

Disclosures: Author has nothing to disclose with regard to commercial support. Received for publication Sept 23, 2014; accepted for publication Sept 26, 2014

Address for reprints: Frank A. Pigula, MD, Department of Cardiothoracic Surgery, Children's Hospital of Boston, 300 Longwood Ave, Farley 144, Boston, MA 02115 (E-mail: Frank.Pigula@tch.Harvard.edu).

J Thorac Cardiovasc Surg 2014;148:2199-200

$0022-5223 / \$ 36.00$

Copyright $(2014$ by The American Association for Thoracic Surgery

http://dx.doi.org/10.1016/j.jtcvs.2014.09.096
}

to the Boston Circulatory Arrest Study (BCAS). A deeper understanding of each is enabled by reviewing the similarities and differences between them.

Let's start with the similarities. Both groups studied neonates undergoing the arterial switch during a similar era (BCAS, 1988-1992; Aachen, 1986-1992), and both groups have performed detailed neurodevelopmental follow-up testing in addition to neuroanatomic imaging with magnetic resonance imaging (MRI) ${ }^{1,2}$ Both groups have reevaluated these patients periodically (ages 4-5, 8-10, and 16-17 years) and have reported significant neurologic impairment across similar domains, primarily in motor skills, language function, and sensory processing skills.

There are, however, some important methodologic differences to note. The BCAS examined the effects of low-flow cardiopulmonary bypass compared to deep 